\title{
Impactos da pandemia Covid-19 no processo formativo de professores de Biologia de um mestrado profissional: desafios em tempos de quarentena
}

\author{
Impacts of pandemic Covid-19 on the training process of Biology teachers from a \\ professional master degree: challenges in quarantine times
}

Douglas Carvalho Amorim ${ }^{1}$

Cleide Jane Araújo Costa ${ }^{2}$

\section{RESUMO}

A pandemia Covid-19 promoveu o isolamento social em escolas e universidades, implicando em mudanças nas formas de estudar e trabalhar. Ela mostrou como alterações no mundo externo à realidade da escola ou universidades podem modificar processos formativos que ocorrem nestes espaços. Neste contexto, a pergunta norteadora deste estudo foi como a pandemia causada pelo novo coronavírus pode influenciar o processo formativo dos estudantes do PPGECIM/UFAL? O objetivo geral do estudo foi investigar como a pandemia influenciou o processo formativo dos estudantes do PPGECIM/UFAL. O estudo apresentou abordagem qualitativa com delineamento exploratório. Os participantes foram cinco professores de Biologia. Os dados foram coletados por meio de entrevistas semiestruturadas e analisados por meio da técnica de análise do conteúdo com auxílio do software Atlas ti 7®. Como principais resultados, os efeitos da pandemia Covid-19 no processo formativo dos mestrandos alterou suas rotinas em aspectos ligados à produção textual, gestão do tempo e processo de produção do produto educacional.

Palavras-chave: Formação de professores; Mestrado profissional; Ensino de Ciências e Matemática; Biologia; Covid-19.

\begin{abstract}
The Covid-19 pandemic promoted social isolation in schools and universities, implying changes in the ways of studying and working. It shows how changes in the world outside the reality of the school can modify training processes that occur in these inner spaces. In this context, a guiding question in this study was how can the pandemic caused by the new coronavirus lead the training process of PPGECIM / UFAL students? The general objective of the study was to investigate how the pandemic influenced the training process of PPGECIM / UFAL students. The study was a qualitative approach with an exploratory design. The

\footnotetext{
${ }^{1}$ Mestre (2015-2017) e doutorando em Tecnologias Digitais da Informação e da Comunicação na Educação (TDIC), Universidade Federal de Alagoas. Maceió, Alagoas, Brasil. E-mail: biotics.edu@ gmail.com

${ }^{2}$ Doutora em Educação (Université de Provence Aix-Marseille I) e em Linguística (UFAL). Atua como professora no Centro de Educação da Universidade Federal de Alagoas, no Programa Modelagem Computacional do Conhecimento (IC) e Programa de Pós-Graduação em Educação Brasileira, Universidade Federal de Alagoas. Maceió, Alagoas. E-mail: cleidejane@gmail.com
} 


\section{Q0 DEVIR EDUCAÇÃO \\ ISSN: 2526-849X}

participants were five Biology teachers. Data were collected through semi-structured interviews and were anylized using the content analysis technique with the aid of the Atlas ti $7 ®$ software. As main results, the effects of the Covid-19 pandemic on the training process of the Master's students changed their routines in connection with textual production, time management and the production process of the educational product.

Keywords: Teacher training; Professional master's degree; Science and Mathematics Teaching; Biology; Covid-19.

\section{Introdução}

Em março de 2020, a Organização das Nações Unidas para a Educação, Ciência e a Cultura (UNESCO) ${ }^{3}$ comunicou que 776 milhões de estudantes do planeta deveriam ser afastados do contexto escolar devido ao número de casos infectados pelo Sars-CoV-2, um novo coronavírus causador da doença Covid-19, transmitida entre seres humanos. Esta situação repercutiu no isolamento social, resultando na implementação de aulas remotas emergenciais em detrimento de encontros presenciais, tanto em escolas como em universidades (ARRUDA, 2020; SANTOS JÚNIOR; MONTEIRO, 2020; VERCELLI, 2020).

O isolamento social ocasionado pela pandemia Covid-19 trouxe desafios em diferentes esferas da vida cotidiana de professores e estudantes no cenário educacional (ARRUDA, 2020), promovendo a discussão em torno do papel das Tecnologias Digitais (TD) na formação permanente de professores e sobre como esta formação é influenciada por fatores que acontecem no cenário escolar e fora dele como as mudanças políticas, educacionais ou socioeconômicas (IMBERNÓN, 2009). Os mestrados profissionais em Educação ou em Ensino de Ciências e Matemática concordam com prerrogativa formativa de que os espaços de trabalho de professores são lócus de identificação e solução de problemas ligados à profissão, traduzidos na forma de dissertação e produto educacional quando o estudante finaliza a etapa formativa (FIALHO; HETKOWSKI, 2017; MOREIRA; NARDI, 2009).

No contexto desta pandemia, considerando que a formação de mestrandos do Programa de Pós-Graduação em Ensino de Ciências e Matemática da Universidade Federal de Alagoas (PPGECIM/UFAL) teve suas aulas presenciais suspensas e aderiu às aulas remotas

${ }^{3}$ Disponível em: https://abmes.org.br/noticias/detalhe/3788/educacao-a-distancia-e-as-voltas-que-aterra-daA?fbclid=IwAR0Q9h-76vRfDjeF128SliNvJQc43H XeOQptJ-25FcAxBV h9at2WcYMjQ. Acesso em 26 jun. 2020.

Revista Devir Educação, Lavras, vol.2, n.4, p.80-103 jul./dez., 2020. 
emergenciais, este estudo levanta o seguinte questionamento: como a pandemia causada pelo novo coronavírus está influenciando o processo formativo dos estudantes do PPGECIM/UFAL?

A hipótese do estudo foi que a situação de pandemia ao provocar mudanças no processo de ensino aprendizagem alterou o processo formativo dos mestrandos em relação à gestão do tempo, produção de dissertação e de concepção de produto educacional.

$\mathrm{O}$ objetivo geral do estudo foi investigar como a pandemia influenciou o processo formativo dos estudantes do PPGECIM durante o primeiro semestre de 2020. Para este propósito, os seguintes objetivos específicos foram trilhados: caracterizar o perfil dos professores de Biologia mestrandos do PPGECIM a partir de dados pessoais e suas concepções sobre o que é formação profissional; identificar as possíveis dificuldades provocadas pelo impacto de isolamento social causado pelo novo coronavírus e que poderiam influenciar na formação acadêmica dos mestrandos; analisar a plataforma online em que as aulas remotas emergenciais de mestrado estão sendo desenvolvidas para estes pósgraduandos, de modo a levantar evidências em torno destes materiais a partir dos recursos que ela oferece, comparando-a com as falas dos mestrandos.

No primeiro momento, discutiremos sobre como os programas de pós-graduação profissionais se diferenciam dos acadêmicos, construindo assim cenário inicial sobre o local e contexto que os sujeitos deste estudo estão inseridos. Discutiremos em seguida sobre o que entendemos por formação permanente de professores e sobre como o ensino, objeto de estudo de programas de pós-graduação em ensino de Ciências e Matemática é um conceito complexo e que envolve diferentes saberes dos professores em torno dele. Articularemos a situação de isolamento social, ocasionada pela pandemia, com o processo formativo de professores, as mudanças tecnológicas necessárias, e as dificuldades enfrentadas por esses atores da educação no contexto atual. Por fim, delinearemos os percursos metodológicos deste estudo e os principais achados nas últimas seções.

\section{Formação permanente de professores em mestrados profissionais de ensino de Ciências e} Matemática

De acordo com a Lei ${ }^{\circ}$ 9.394/96 de Diretrizes e Bases da Educação Nacional, a educação superior abrange cursos de pós-graduação por meio de especializações, mestrados e doutorados (BRASIL, 2018). Dentro dos mestrados, existem aqueles denominados profissionais e os acadêmicos. Segundo Fialho e Hetkowski (2017) a pós-graduação 


\section{QO DEVIR EDUCAÇÃO}

ISSN: 2526-849X

profissional visa formar profissionais para atuarem em seu campo específico de mercado de trabalho, com objetivos um pouco diferentes dos mestrados acadêmicos que formam profissionais também para a carreira acadêmica.

Ainda que se assemelhem em alguns aspectos aos mestrados educacionais, os mestrados profissionais possuem suas peculiaridades. De acordo com Fialho e Hetkowski (2017), nos mestrados profissionais em Educação se enfatizam problemas ligados à formação de professores ou ligados aos sistemas de ensino. Realizando um recorte mais específico, dentro da formação de professores, o ensino representa um dos problemas de investigação que reflete a formação destes profissionais.

No que se refere aos mestrados profissionais de Ensino de Ciências e Matemática, Moreira e Nardi (2009) afirmam que eles têm se expandido pelo Brasil, melhorando o ensino de Biologia, Física, Química e Matemática, mas têm enfrentado dificuldades de identidade por serem confundidos como variantes dos mestrados acadêmicos ou especializações.

Ainda segundo Moreira e Nardi (2009) os mestrados profissionais em ensino de Ciências e Matemática visam contribuir com a formação continuada de professores e possuem as seguintes características: possuem disciplinas específicas das áreas de formação dos professores e disciplinas educacionais comuns a todas as áreas; são localizados em uma unidade acadêmica; são constituídos por professores atendendo diferentes licenciaturas; podem ter duração de até 36 meses como prazo máximo para apresentação do trabalho final; podem ser complementados com atividades à distância; de 30 a 50\% da carga horária total do curso é voltada a disciplinas obrigatórias de conteúdos de Ciências e Matemática; os pósgraduandos devem apresentar trabalho de conclusão de curso e produto educacional, consistindo no primeiro caso em um relato de experiência de implementação de estratégias didáticas ou dos produtos educacionais produzidos.

Segundo Moreira e Nardi (2009), os produtos educacionais oriundos dos mestrados profissionais podem ser um aplicativo, uma sequência didática, um jogo, um filme documentário, etc. que possam ser disseminados para uso por outros professores. Os autores concluem que todas estas ênfases dadas no mestrado profissional podem mudar de acordo com o tempo e contexto. A presença de disciplinas de natureza pedagógica e epistemológica deve constar na estrutura curricular, dando destaque à aprendizagem e à natureza do conhecimento. Por fim, os autores concluem que o foco do mestrado profissional deve ser a aplicação do conhecimento e não a produção do conhecimento acadêmico e que a pesquisa 


\section{OO DEVIR EDUCAÇÃO}

ISSN: 2526-849X

precisa estar subjacente, mas não como principal objetivo. Fialho e Hetkowski (2017) complementam afirmando que os mestrados profissionais em educação são espaços formativos e investigativos voltados para a atuação de professores que articulam a educação superior com a educação básica.

Neste sentido, os mestrados profissionais voltados para professores enfatizam a aplicabilidade do conhecimento na vida profissional, refletindo no amadurecimento formativo destes sujeitos que articulam os conhecimentos adquiridos nas universidades à prática na educação básica, lócus da ação profissional. Ainda que a ênfase de Fialho e Hetkowski (2017) tenha sido dada a mestrados profissionais em Educação, portanto, mais abrangentes, a proposta é a mesma dos mestrados profissionais para o Ensino de Ciências e Matemática (MOREIRA; NARDI, 2009). De acordo com Fialho e Hetkowski (2017, p.30) uma das perspectivas do mestrado profissional em Educação é "o trato de problemáticas educacionais inerentes aos ambientes profissionais como parte integrante de processos formativos, de pesquisa e desenvolvimento de produtos voltados para o uso, geração e experimentação de materiais, técnicas, projetos, metodologias e aplicativos”. Neste sentido, as práticas no ambiente de trabalho, com a identificação de problemas, resultam em contribuições no processo formativo de professores por meio da criação de produtos educacionais e textuais ao refletirem sobre suas próprias práticas no processo construtivo.

\section{A formação permanente de professores: complexidade e desafios}

Concordamos com Formiga (2009), ao afirmar que a educação, de modo geral, vai além dos muros escolares ou de universidades, e compreende todos os processos formativos que os sujeitos passam ao longo da vida. Neste sentido, ao discutirmos sobre formação de professores não estamos reduzindo-a a prática de ensinar, mas a uma complexidade que envolve o ensino e outros fatores. De acordo com Imbernón (2009), o percurso formativo depende das mudanças que ocorrem em contextos sociais, políticos e educativos. A formação, para o autor, não está desvinculada da realidade externa que a cerca e a formação permanente está ligada à capacidade dos professores em compreenderem o que vão ensinar, mas também como irão ensinar. Assim, a metodologia de ensino não está desarticulada dos conteúdos.

Revista Devir Educação, Lavras, vol.2, n.4, p.80-103 jul./dez., 2020. 
$\mathrm{Na}$ formação permanente, prioriza-se as práticas desenvolvidas por professores em seus espaços de trabalho (IMBERNÓN, 2009) e isto condiz com o cenário criado em torno dos mestrados profissionais em ensino de Ciências e Matemática ao priorizarem as ações pedagógicas dos mestrandos em salas de aula (MOREIRA; NARDI, 2009). Para Imbernón (2009), não se pode mais conceber a formação como o domínio de disciplinas científicas ou acadêmicas, mas como modelos relacionais, colaborativos e participativos dos professores em seus espaços de trabalho. Para o autor, eles precisam estar atentos às mudanças do mundo globalizado e com os avanços tecnológicos que podem influenciar as práticas de ensino cotidianas que eles desenvolvem deixando de lado a tradição exclusiva de leitura de textos.

A formação docente está ligada ao ensino, mas não se resume a ela. De acordo com Tardif (2014), no percurso formativo de professores há o desenvolvimento de saberes diversificados e que se traduzem na complexidade da profissão docente. O "saber" para o autor significa os conhecimentos, o saber-fazer, as competências e habilidades que os professores mobilizam no cotidiano das escolas, nas salas de aula, com a finalidade de realizar suas tarefas. $\mathrm{O}$ ensino é apenas um destes saberes que fazem parte do processo formativo dos professores.

Outros saberes discutidos por Tardif (2014) são: saberes disciplinares (o conhecimento dos conteúdos da disciplina específica), curriculares, profissionais (que inclui os conhecimentos pedagógicos) e os experienciais. Todos eles se traduzem na forma que o professor ensina em sala de aula. O modo de ensinar do professor é resultante das vivências prévias dele à escola, considera as experiências dele em espaços formais e sua atuação em sala de aula após a sua passagem pela universidade. Assim, a forma que ele ensina dialoga com sua história de vida. Daí a complexidade em torno da ação de ensinar e como ela pode se modificar ao longo do tempo, o que concorda com Imbernón (2009) quando o autor enfatiza que a formação contínua dos professores é diretamente influenciada por mudanças externas: as decisões tomadas nas escolas, as decisões políticas, as mudanças socioeconômicas, etc. Nas palavras do autor "a formação do professorado está influenciada tanto pelo contexto interno (escola) como pelo contexto externo (comunidade)" (IMBERNÓN, 2009, p.29).

Ainda que a ação de ensinar seja complexa e envolva os saberes que os professores desenvolvem ao longo da vida, seguimos a compreensão na mesma perspectiva de Tardif (2014, p.118) quando diz que "ensinar é desencadear um programa de interações com um grupo de alunos, afim de atingir determinados objetivos educativos relativos à aprendizagem 
de conhecimentos e à socialização". Essa perspectiva de ensino se alinha com a noção de formação permanente levantada por Imbernón (2009), ao afirmar que a formação não é isolada, mas é realizada em colaboração com pares como estudantes e os demais atores da vida cotidiana de trabalho.

A partir do pressuposto de que a formação contínua preconizada por Imbernón (2009) é influenciada por aspectos internos, que ocorrem na escola e sala de aula, e externos, em um contexto societário, e que ensinar é uma ação que acompanha o histórico de vida dos professores, as vivências de diferentes saberes que influenciam no modo que o ensino se desenvolve (TARDIF, 2014), iremos agora analisar os impactos que a pandemia Covid-19 no cenário da pós-graduação e como isto pode influenciar no percurso formativo de professores em suas atividades dentro e fora das escolas, os principais desafios e mudanças quanto à ação de ensinar que esperam estes profissionais após a pandemia.

\section{Covid-19 e formação de professores: desafios e mudanças}

Se para Imbernón (2009) um dos pressupostos da formação permanente de professores é que eles saibam o que vão ensinar, mas também como irão ensinar e que este percurso formativo é influenciado por fatores externos, como mudanças no cenário educacional, político e socioeconômico, o advento da doença Covid-19 e do isolamento social redesenhou a forma de ensinar e aprender, afetando atividades na educação básica e superior por meio da suspensão de aulas presenciais (VERCELLI, 2020) e a implementação de aulas remotas emergenciais (ARRUDA, 2020).

Segundo Arruda (2020) as aulas remotas emergenciais podem ser compreendidas

como lives ${ }^{4}$ que são realizadas por professores das aulas que ocorriam anteriormente à pandemia em um contexto presencial sob mesmo horário fixo. De acordo com Santos Júnior e Monteiro (2020), estas aulas podem ser desenvolvidas, por exemplo, por meio de webconferências (gravação de vídeos síncronos, ou seja, ao vivo) ou audioconferências (gravação de voz).

\footnotetext{
${ }^{4} \mathrm{O}$ sentido de lives que utilizamos neste texto é o de chamadas ao vivo para interação no contexto online.
} 


\section{Q0 DEVIR EDUCAÇÃO \\ ISSN: 2526-849X}

Segundo Moreira, Henrique e Barros (2020), essa transição de ensino presencial para o online por meio de lives ocorreu de modo compulsório e as práticas desenvolvidas na sala de aula física foram transpostas e com o mesmo teor de transmissão do conhecimento no contexto virtual. Os autores mencionam que estas aulas remotas abrangem diferentes plataformas de apoio ao ensino, a saber: Youtube, Skype, Google Hangout e o Zoom, todas auxiliando o professor por meio de viodeconferência e, para a aprendizagem, plataformas como Moodle, Microsoft Teams e Google Classroom possibilitam que estudantes complementem seus conhecimentos. Os autores acrescentam que a pandemia "obrigou" os professores a reinventarem suas práticas, assumindo novos papéis e se a comunicarem de modos que não estavam habituados.

O surgimento do novo coronavírus modificou a rotina de professores e estudantes de modo que desafios surgiram, a saber: a qualidade do trabalho dos professores pode ser prejudicada pela divisão da atenção com rotinas caseiras; falta de equidade na acessibilidade às Tecnologias Digitais (TD) pelos atores da educação; rotina dos estudantes dividida com distrações ou outras atividades caseiras (ARRUDA, 2020; SANTOS JÚNIOR; MONTEIRO, 2020).

No cenário atual provocado pelo novo coronavírus, percebe-se que os pressupostos levantados por Imbernón (2009) de que mudanças educativas, socioeconômicas ou tecnológicas influenciam a formação permanente de professores são reafirmados, levando-os à reflexão para além do que ensinam, mas sobre como ensinam. Também que, neste contexto emergencial de mudanças e de improviso, os saberes experienciais dos professores (TARDIF, 2014), ou seja, suas vivências prévias com pessoas, objetos e situações, influenciam no contexto atual, sobre como eles se relacionam com a tecnologia, seja por meio de plataformas para realização de lives ou ao complementar o conteúdo ensinado em plataformas assíncronas (ARRUDA, 2020; SANTOS; MONTEIRO, 2020; MOREIRA; HENRIQUE; BARROS, 2020).

Em meio à paralisação de aulas presenciais na graduação e pós-graduação em todo o país e, neste último caso, a continuidade por meio de aulas remotas, com base na decisão de cada universidade em aderi-las ou não, Vercelli (2020) investigou quais são as percepções de estudantes de um mestrado profissional em Educação sobre as aulas remotas implementadas pelo novo coronavírus. Seus resultados revelam que as aulas remotas mantiveram a mesma qualidade que as aulas presenciais, com engajamento entre professor e estudantes, destinação

Revista Devir Educação, Lavras, vol.2, n.4, p.80-103 jul./dez., 2020. 


\section{OD DEVIR EDUCAÇÃO \\ ISSN: 2526-849X}

de um tempo maior para a realização de atividades pelos estudantes uma vez que no período de quarentena não precisavam se deslocar à universidade, o que também refletiu na economia financeira com transporte público e alimentação. Nossa investigação, contudo, objetivou analisar quais os possíveis desafios do ensino remoto para o percurso formativo de mestrandos de um Programa de Pós-Graduação em Ensino de Ciências, com viés profissional, situado em uma universidade federal. Na próxima seção delineamos as trilhas investigativas para este propósito.

\section{Caminhos metodológicos}

Este estudo apresenta abordagem qualitativa com delineamento exploratório. Por abordagem qualitativa entendemos todo tipo de pesquisa cujos resultados não sejam alcançados por meio de procedimentos estatísticos ou por outro modo de quantificação (STRAUSS; CORBIN, 2008), que busque compreender a realidade da vida das pessoas, suas opiniões, percepções, condições contextuais em que as pessoas vivem, as relações entre conceitos existentes e emergentes e que se utiliza de múltiplas fontes de evidência (YIN, 2016). O delineamento exploratório, por sua vez, examina temas ou problemas de pesquisa pouco estudados, em que temos ainda muitas dúvidas e que não foi abordado antes, ou seja, fenômenos desconhecidos ou novos (SAMPIERI; COLLADO; LUCIO, 2013). Em nosso contexto, investigamos como o isolamento social provocado pelo novo coronavírus influenciou na formação permanente de professores de Biologia mestrandos do PPGECIM/UFAL.

Os sujeitos do estudo foram cinco professoras mestrandas do PPGECIM/UFAL ingressas no ano de 2019. Considerando como critérios de inclusão, a matrícula institucional no semestre 2020.1 deveria estar em vigor e optarem por participar voluntariamente da pesquisa. Para este propósito, contatamos a coordenação do PPGECIM via e-mail, solicitando o e-mail das mestrandas. Todas decidiram participar voluntariamente do estudo. Apresentamos o Termo de Consentimento Livre e Esclarecido (TCLE), esclarecendo os objetivos da pesquisa e sobre como elas participariam dele. 
Os dados foram coletados por meio de entrevistas semiestruturadas (SAMPIERI; COLLADO; LUCIO, 2013) com roteiro pré-estabelecido. Cada entrevista durou em média cinqüenta minutos e foram gravadas. Após as transcrições, apresentamos os materiais às mestrandas de modo que pudessem conferir se o que disseram correspondia ao que realmente queriam ter dito no primeiro momento. Este procedimento confere maior confiança nos dados qualitativos, evitando que concepções subjetivas do pesquisador fossem colocadas na análise dos dados posteriormente (SZYMANSKY, 2011).

Utilizamos a técnica análise do conteúdo (BARDIN, 2011) após transcrever os dados no software Microsoft Word e inseri-los posteriormente no software de análise de dados qualitativos Atlas $t i{ }^{7}{ }^{5}$. As etapas das análises foram: (a) pré-análise: compreende o primeiro contato com os dados brutos por meio da leitura flutuante sobre o material, evidenciando inicialmente as categorias do estudo; (b) tratamento dos dados brutos: ocorre a codificação do texto, de modo a organizar cada trecho nas categorias do estudo; (c) interpretação dos resultados: após o agrupamento dos trechos em categorias, realiza-se inferências em torno dos achados de modo a interpretar e responder ao problema do estudo. As categorias previamente definidas do estudo foram: Concepção sobre formação permanente; Produto educacional e formação; Desafios de formação na pandemia; Covid-19 e formação pós-pandemia.

Neste contexto, este estudo foi divido em duas etapas: a primeira consistiu em traçar o perfil dos sujeitos do estudo e analisar como a pandemia Covid-19 influenciou o seu processo formativo; a segunda, analisar a plataforma online que os sujeitos do estudo estão tendo aulas remotas, de modo a inferir em torno da qualidade das aulas ministradas a eles a partir dos recursos que a plataforma oferece, comparando os achados com aqueles trazidos nas entrevistas realizadas na primeira etapa. A partir destes pressupostos, discutiremos na próxima seção os achados do estudo.

\section{Impactos da pandemia Covid-19 no percurso formativo de mestrandos de Biologia do PPGECIM/UFAL}

\footnotetext{
${ }^{5}$ Para maiores informações, acessar: https://atlasti.com/
} 
Nessa primeira etapa, traçamos o perfil dos sujeitos do estudo de modo a termos uma visão ampla em torno do contexto de isolamento social provocado pela pandemia Covid-19 que estão vivendo em termos acadêmicos atualmente. Identificamos os professores por meio das letras A, Y, L, R e J de modo a preservar as suas identidades. $\mathrm{O}$ quadro 1 apresenta a caracterização dos mestrandos.

Quadro 1 Perfil dos mestrandos de Biologia do PPGECIM/UFAL ingressos no ano 2019

\begin{tabular}{|c|c|c|c|c|c|}
\hline Características & $\mathbf{A}$ & $\mathbf{Y}$ & $\mathbf{L}$ & $\mathbf{R}$ & $\mathbf{J}$ \\
\hline Sexo & Feminino & Feminino & Feminino & Feminino & Feminino \\
\hline Idade & 35 & 27 & 23 & 25 & 26 \\
\hline Estado civil & Casada & Solteira & Solteira & Solteira & Solteira \\
\hline $\begin{array}{c}\text { Filhos ou } \\
\text { dependentes }\end{array}$ & $\operatorname{Sim}(1)$ & Não & Não & Não & Não \\
\hline $\begin{array}{l}\text { Título do } \\
\text { projeto de } \\
\text { dissertação }\end{array}$ & $\begin{array}{l}\text { Gerenciamento de } \\
\text { resíduos sólidos } \\
\text { por uma } \\
\text { abordagem } \\
\text { learning by doing } \\
\text { no ensino de } \\
\text { Ciências }\end{array}$ & $\begin{array}{c}\text { O self e a } \\
\text { reconstrução da } \\
\text { identidade de } \\
\text { professores de } \\
\text { Ciências diante dos } \\
\text { desafios do mundo } \\
\text { globalizado }\end{array}$ & $\begin{array}{l}\text { Literatura de } \\
\text { cordel: um } \\
\text { elo entre } \\
\text { cultura e } \\
\text { ensino de } \\
\text { Citologia }\end{array}$ & $\begin{array}{l}\text { Alfabetização } \\
\text { Científica no } \\
\text { ensino de } \\
\text { Ciências na } \\
\text { EJA: } \\
\text { realidades e } \\
\text { vivências (re) } \\
\text { significadas }\end{array}$ & $\begin{array}{l}\text { Ainda não } \\
\text { definido. }\end{array}$ \\
\hline $\begin{array}{c}\text { Produto } \\
\text { educacional }\end{array}$ & $\begin{array}{l}\text { Manual de } \\
\text { gerenciamento de } \\
\text { resíduos sólidos } \\
\text { em instituição } \\
\text { educacional }\end{array}$ & Ainda não definido. & $\begin{array}{l}\text { Ciência em } \\
\text { verso de } \\
\text { cordel: uma } \\
\text { sequência } \\
\text { didática para } \\
\text { o ensino de } \\
\text { Citologia }\end{array}$ & $\begin{array}{l}\text { Ainda não } \\
\text { definido. }\end{array}$ & $\begin{array}{l}\text { Ainda não } \\
\text { definido. }\end{array}$ \\
\hline
\end{tabular}

Fonte: Elaborado pelos autores

A partir da análise do quadro 1, constatamos que os sujeitos do estudo são do sexo feminino, possuem em média 27 anos, são majoritariamente solteiras e sem filhos ou dependentes para dedicar seu tempo a cuidados. A partir destes dados iniciais, podemos inferir que a professora $\mathrm{A}$ teve maior dificuldade na distribuição de seu tempo às atividades profissionais da escola em que trabalha, assim como aquelas ligadas ao mestrado, como produção de texto ou criação do produto educacional (MOREIRA; NARDI, 2009). Quanto às demais professoras, podemos inferir que o tempo de atividades de mestrado foi dividido para a ajuda em atividades do lar, somente. Também a partir da análise do quadro 1 constatamos que os temas de interesse para dissertação e produto educacional são diversificados e que, ainda que sejam professoras de Biologia, o interesse maior quanto ao texto e produto educacional é para o ensino de Ciências no ensino fundamental II. A mestranda Y teve que readaptar o produto educacional e a $\mathrm{J}$, tanto o texto quanto o produto educacional em função 
do isolamento social causado pela pandemia. Isto evidencia como mudanças externas influenciam em processos formativos práticos ligados ao ensino (IMBERNÓN, 2009).

Após essa caracterização inicial, questionamos as mestrandas sobre suas concepções em torno do significado de "formação profissional". Chegamos a diferentes resultados:

A: "formação é um processo de construção escolar ou profissional[...]"

Y: "é um processo de construção em que pessoas são moldadas por meio de saberes que são adquiridos ao longo do tempo"

L: "formação é um processo contínuo na vida de uma pessoa para aquisição de conhecimentos elou hábitos em diversos âmbitos da sociedade, seja intelectual, ético, moral [...]."

R: "[...] maneiras de construção educacional, independente de ser formal ou não"

$\mathrm{J}$ : "um processo contínuo para qualquer profissão, principalmente para a docência, pois ensinar e aprender faz parte de uma rotina diária"

A partir dos dados apresentados, a definição de formação profissional para as mestrandas é um processo contínuo em construção que ocorre dentro e fora da escola, em diversos âmbitos sociais e é moldada por saberes ao longo do tempo, envolvendo a prática de ensinar e aprender. A partir destes achados, podemos afirmar que as professoras ao realizar o mestrado profissional não desassociam os saberes de suas vidas pessoais das práticas que ocorrem dentro e fora da sala de aula, como já constatado por Tardif (2014) e articulam o ensino (como na fala da professora $\mathbf{J}$ ) como parte deste processo formativo proposto pelo mestrado profissional (IMBERNÓN, 2009; MOREIRA; NARDI, 2009). Estes aspectos são reafirmados quando questionamos se a criação do produto educacional influencia no processo formativo das mestrandas. Alguns trechos principais de suas falas são apresentados a seguir:

A: "Sim! Porque há muito material potencialmente reciclável produzido em uma escola [vou ajudar a otimizar este processo/reflexo na formação]."

Revista Devir Educação, Lavras, vol.2, n.4, p.80-103 jul./dez., 2020. 
Y: "Como é o Self docente [...] poderei aprender com minha prática e o estudante comigo. Influencia sim na minha formação, porque vou ter um novo olhar sobre o ensino".

L: "o produto educacional traz muito do que o professor acredita, baseada nas experiências em sala de aula e leituras [prévias][...] penso que na aplicação do produto muita coisa se modifica, devido aos desafios e situações inesperadas".

R: "[...] vejo meu produto educacional como uma forma de aplicação em meu cotidiano profissional daquilo que estou desenvolvendo na teoria".

J: "a construção do produto também faz parte da formação e poderá ser utilizado por outros professores deixando também uma contribuição para sociedade".

A partir da análise dos dados, verificamos que as mestrandas vinculam a criação do produto educacional à sua formação profissional, sendo ele resultado de suas experiências, vivências prévias, leituras, e que a prática de criá-lo é uma oportunidade para enxergar a ação de ensinar de forma diferenciada e sempre vinculada ao cotidiano do trabalho. O trecho final da fala da mestranda $\mathrm{J}$ "e poderá ser utilizado por outros professores deixando também uma contribuição para a sociedade" pressupõe um dos objetivos principais de um mestrado profissional, com resultados diversificados (MOREIRA; NARDI, 2009) e que aproximam a educação superior da educação básica (FIALHO; HETKOWSKI, 2017). Segundo Tardif (2014) os professores apresentam diferentes saberes e o experiencial é observado na fala da mestranda L estando refletido na ação de ensinar colocada logo a seguir por ela, em que desafios surgem com a prática. A fala da professora Y, por sua vez, se aproxima da concepção de Imbernón (2009) de que na formação o professor pensa no que ensinar, mas também em como ensinar, e este último ponto é traduzido na fala da mestranda como "um novo olhar sobre o ensino".

No tocante aos impactos que a pandemia causada pelo novo coronavírus no processo educativo das mestrandas, os principais achados foram: a interrupção nas atividades escolares, de modo a retardar o processo produtivo, como mencionado pela mestranda A. Na fala da mestranda $\mathrm{R}$ “nem sempre é possível ser produtivo sabendo que muitas pessoas estão morrendo e muitas vezes conhecidos e familiares". Ela acrescenta que foi frustrante sair da graduação, entrar no mestrado e ter as aulas presenciais interrompidas abruptamente. A 


\section{OO DEVIR EDUCAÇÃO}

ISSN: 2526-849X

mestranda Y afirma que "presencialmente, as discussões e debates são mais proveitosos que a distância [...] não me sinto tão motivada [...] as trocas de experiências ficou bem reduzida e não é enriquecedora [...] em meu processo formativo isto deixa a desejar". Mas ela também acrescenta "estamos aprendendo novas formas de ensinar e aprender [...] abrindo nossos olhos para novas formas de ensinar e aprender [...] tem seu lado positivo para evoluirmos como profissionais". A preocupação mestranda L recaiu sobre os prazos que devem ser atendidos no mestrado ao afirmar que "devido o fechamento das instituições escolares, não foi possível realizar nem primeiras etapas do projeto e isto tem me deixado bastante preocupada e ansiosa" e complementa "isto tem me deixado sobrecarregada". A fala da mestranda $\mathrm{J}$ recai sobre o comprometimento da pesquisa e nas relações interpessoais fundamentais ao processo formativo.

A partir destes achados, podemos afirmar que questões ligadas à gestão do tempo, dos aspectos emocionais e da preocupação quanto ao andamento dos estudos pelas mestrandas são os principais impactos gerados pelo isolamento social. De acordo com Arruda (2020), o novo coronavírus gerou mudanças nas rotinas cotidianas de diferentes pessoas e, no caso das mestrandas, sobrecarga de trabalho devido à interrupção das aulas em seus locais de trabalho. Se para Fialho e Hetkowski (2017) os mestrados profissionais cumprem o papel de formar profissionais altamente qualificados, o estudo atual aponta que esta qualidade está ligada ainda mais à forma que os estudantes conseguem gerir o tempo para o desenvolvimento das atividades requeridas e nos prazos estabelecidos. Contudo, o impacto positivo foi o novo olhar sobre como ensinar e aprender, aspectos ligados à formação (IMBERNÓN, 2009) e mencionados pela mestranda Y.

Ao questionarmos sobre o impacto das aulas emergenciais sobre o processo formativo, encontramos os seguintes resultados: A mestranda A afirmou que ajuda a "acelerar a conclusão do curso e a adaptação de horários"; A mestranda Y, por outro lado, afirmou que as aulas remotas podem afetar sua formação porque "a troca de experiências não é a mesma que a presencial [...] apesar de termos as tecnologias [celulares, smartphones, Google Meet], ainda estamos aprendendo a utilizá-las [...] tem o lado negativo e positivo". Esta perspectiva contrasta com a da mestranda L, ao afirmar que "estamos tendo aulas por meio do Google Meet. [...]. Até o momento, as discussões nas aulas têm sido muito produtivas". A visão da mestranda $\mathrm{R}$, contudo, concorda com a mestranda $\mathrm{Y}$, ao afirmar "vejo como uma alternativa perante a situação que estamos [vivendo] e estou gostando da experiência. O que complica é 
que muitas vezes a conexão [da internet] não coopera". Por fim, a mestranda J afirma que "Não conclui todas as disciplinas, por isso sou a favor das aulas remotas, tendo em vista as atividades assíncronas e síncronas para que não houvesse a necessidade de prolongamento do mestrado".

A partir destes achados, podemos afirmar que a visão em torno do impacto da pandemia no processo formativo gerou diferentes percepções nas mestrandas: por um lado, falta de contato pessoal e baixa qualidade de acesso à internet como aspectos negativos; por outro, continuidade dos estudos e produtividade nas aulas remotas foram os pontos positivos. Segundo Arrunda (2020), a interrupção total das aulas geraria distanciamento entre os atores da educação, comprometendo a qualidade no contexto pós-pandemia.

Ainda na perspectiva de aulas remotas, quando questionamos se elas têm a mesma qualidade que as aulas presenciais, chegamos aos seguintes resultados: a mestranda $\mathrm{A}$ não emitiu sua concepção em relação a esta questão. A mestranda Y afirmou que "não seria! Não tem contato 'olho no olho' ou ouvir de perto o que o outro pensa. Presencialmente é muito mais enriquecedor do que quem está por trás de uma tela de computador ou celular [...] o processo formativo não é o mesmo". Ela também acrescenta que "o [ensino] presencial enriquece mais a troca de saberes que a distância, que é muito limitada porque não 'sentimos' as outras pessoas". Esta resposta contrasta com a trazida pela mestranda L, ao afirmar que inicialmente tinha preconceito em relação às aulas remotas, mas que depois "as experiências que venho tendo com recursos digitais tem modificado minha visão [...] as aulas remotas têm sido produtivas, não muito diferentes das aulas presenciais". Ela ainda menciona que por morar no interior do Estado de Alagoas, tinha que se deslocar para a capital, o que a deixava muito cansada e isto influenciava na sua aprendizagem. Com as aulas remotas, o esgotamento físico ficou em segundo plano e pode aprender melhor. Contudo, acrescenta perdas que podem existir, como atividades práticas que não existem mais. A estudante $R$ reafirmou sobre a conexão da internet, dizendo que esta influencia na qualidade das aulas remotas negativamente; e a participante $\mathrm{J}$ sobre isso disse que "A qualidade não é a mesma, pois o contato pessoal é fundamental, mas temos que lembrar que a prevenção [da contaminação do vírus] é a melhor forma para evitar as patologias". A mestranda A não emitiu sua concepção em relação a essa questão.

Os saberes experienciais (TARDIF, 2014) são articulados nas falas da mestranda Y e L e que, a partir destes achados, eles podem se desenvolver presencialmente ou online, 
contribuindo no processo formativo. A perda na qualidade das aulas remotas está também ligada a este tipo de saber, uma vez que aulas práticas estão ausentes e quando ocorrem no contexto online, a conexão à internet pode atrapalhar a vivência.

Ao questionarmos sobre como a pandemia influenciou no processo de escrita da dissertação, chegamos aos seguintes resultados: a mestranda A afirmou que "inicialmente, sem aulas, eu conseguia caminhar um pouco mais em relação à escrita, mas depois com a sobrecarga de aulas [remotas da escola], trabalho, educação de filhos e serviço doméstico tem sido difícil escrever". A mestranda $\mathrm{Y}$ afirmou que "estou com menos tempo para escrever. Sou da rede particular de ensino e estou com mais trabalho em casa do que se estivesse na escola". Contudo, a mesma mestranda acrescenta um dado que se relaciona ao tema de sua dissertação: “[...] mas [a pandemia] ajudou na forma da escrita porque a visão da dissertação é voltada para a reflexão de professores sobre novas metodologias de ensino, permitindo que o professor se reinvente". A estudante L acrescenta que teve impacto positivo na escrita, ao menos inicialmente, ao afirmar que "a demora com que as aulas retornaram [no modo remoto], possibilitou 'mais tempo' para a realização de leituras e produção da fundamentação, apenas". Esta realidade contrasta com a apresentada pela professora R, ao afirmar que

"depende do contexto de cada um [...] sou professora e tive que me readaptar para ensinar na educação básica [na pandemia] e isto é mais trabalhoso que as aulas presenciais [...]. No início da pandemia a produtividade na escrita da dissertação caiu bastante, mas em seguida fui reorganizando os horários".

Essa perspectiva vai ao encontro do que foi dito pela mestranda $\mathrm{J}$, ao afirmar que "influenciou na organização do tempo dedicado à escrita porque para quem trabalha, a carga horária aumentou".

Assim, na escrita do texto científico, a pandemia impactou na gestão de tempo e foi um dos aspectos mencionados como mais difícil devido à sobrecarga de trabalho nas escolas (ARRUDA, 2020). A inferência que realizamos em relação à mestranda A no quadro 1 foi confirmada nesta etapa na entrevista: seu tempo foi dividido com muitas atividades domésticas e cuidados com o filho, de modo a retardar a escrita da dissertação. As mestrandas Y e L, contudo, apresentaram pontos positivos: reflexão em torno da escrita e a melhor gestão 


\section{OO DEVIR EDUCAÇÃO}

ISSN: 2526-849X

do tempo, neste último ponto concordando com os achados do estudo de Verceli (2020) sobre as percepções de estudantes sobre os impactos das aulas remotas na pandemia Covid-19.

Em seguida, questionamos as mestrandas se o isolamento social devido à pandemia modificou a ideia em torno do produto educacional a ser produzido como requisito do curso. Obtivemos os seguintes resultados: a mestranda A, afirmou que "o meu produto educacional pode sofrer mudanças, mas acredito que poucas coisas". A mestranda Y, também afirmou que "não modificou, mas abriu mais a minha visão para estas práticas [reflexivas] educacionais. O professor precisa se reinventar agora com outras metodologias que a gente nem sabia que existiam por estarmos em uma sala de aula tradicional" ela também acrescenta que "somos agora obrigados a buscar novas formas de ensino e aprendizagem e esta pandemia fez com que a gente se reinventasse na área de educação pela busca maior de novas metodologias". Ainda que a mestranda Y não tenha ainda definido seu produto educacional ela evidencia que a pandemia influenciou na forma que o mesmo será construído, ocorrendo o mesmo com a mestranda $\mathrm{R}$, todavia esta participante pensa em realizar uma sequência didática. A mestranda $\mathrm{L}$ afirmou que as possíveis mudanças em seu produto estão sendo avaliadas devido à pandemia; a $\mathrm{J}$ revela que suas ideias em torno do produto estão em reconstrução para adaptá-lo às condições atuais.

A fala da mestranda $\mathrm{Y}$ traduz que a forma de ensinar é uma ação reflexiva, que é influenciada por fatores externos a exemplo das tecnologias e do mundo globalizado (IMBERNÓN, 2009). A obrigatoriedade das mudanças de aulas presenciais para remotas trazidas pela Covid-19 (ARRUDA, 2020) despertou o interesse das participantes deste estudo para explorar outros caminhos metodológicos para ensinar e aprender. Relatam ainda que as ideais em torno do produto educacional mudaram devido ao evento pandêmico para algumas destas mestrandas devido ao novo contexto apresentado.

Ao questionarmos sobre quais principais desafios foram levantados ao processo formativo no PPGECIM devido à pandemia Covi-19, os principais pontos apresentados foram: organização de tempo em casa para atender múltiplas demandas; disponibilidade de recursos tecnológicos usado para assistir aulas como o smartphone e laptop, uma vez que não tinham hábitos de utilizá-los para este fim; episódios de ansiedade; ausência de espaço físico em suas casas para organizar os estudos pessoais; situação de improviso dada pela pandemia; modificação do espaço em que a pesquisa vai ser desenvolvida. Neste sentido, além dos desafios apresentados por Arruda (2020), Santos Júnior e Monteiro (2020), este estudo 
revelou que a ansiedade desencadeada para prosseguir com estudos e falta de hábito de uso de tecnologias precisam ser superadas pelas mestrandas. A falta de acessibilidade às tecnologias, contudo, não foi mencionada.

Por fim, questionamos se os impactos provocados pelo novo coronavírus na educação modificaram a visão das mestrandas sobre práticas educacionais e como elas enxergam suas atuações enquanto professoras em um contexto pós-pandemia. A mestranda A afirmou que "terei uma visão mais holística em torno do que é educação e é difícil prever como serão minhas práticas após este período. Mas espero que sejam melhores, plurais e empáticas". A mestranda $\mathrm{Y}$ afirmou que "abriu mais minha visão para novas práticas educacionais com outras metodologias e, após a pandemia, sairei com experiências melhores, porque tive que buscar formas alternativas para que meus alunos aprendessem. Eu era acomodada na questão de tecnologias". A participante acrescenta: "tem sido uma experiência inovadora para melhorar o ensino". Concordando com esta visão, a estudante L afirmou que sua percepção

\footnotetext{
"modificou totalmente. Consigo agora enxergar as tecnologias com outros olhos, contribuindo para a construção do conhecimento científico, comunicação e otimização de tempo e espaço [...] após a pandemia estarei mais engajada em formar pessoas, entendendo diversidades $e$ integrando diversos assuntos que envolvam tecnologia, sociedade e meio ambiente".
}

A visão da mestranda A sobre educação concorda com os pressupostos de Formiga (2009), de que educação envolve todos os processos formativos do ser humano e vai além dos muros escolares ou de universidades, sendo isto uma "visão holística" como ela apresentou. A visão e reflexão sobre como ensinar (IMBERNÓN, 2009) são retomadas na fala da mestranda $\mathrm{Y}$, vinculada com a interação dela com as TD e, a partir de saberes experienciais (TARDIF, 2014) que podem ser desenvolvidos no período pandêmico, uma vez que ela menciona "sairei com experiências melhores". O diálogo entre processos internos, inerentes à escola, e a sociedade levantado por Imbernón (2009) é verificado na fala da mestranda L, ao articular tecnologia, sociedade e meio ambiente no contexto pós-pandemia, imprescindíveis ao seu processo formativo profissional.

A estudante $\mathrm{R}$ enfatizou que a pandemia, no cenário educacional “ajudou a enxergar as possibilidades e o quanto somos capazes de inovar e melhorar a prática educacional[...] e 


\section{OO DEVIR EDUCAÇÃO}

ISSN: 2526-849X

após a pandemia, serei uma profissional mais empática, humanizada, capacitada nas tecnologias digitais e flexível nos conteúdos curriculares”. Ela também acrescenta que "preciso ouvir mais os meus alunos e que muitas vezes, esse ouvir, vale mais do que uma hora aula de conteúdo programático, afinal, estamos todos no mesmo barco com medos e anseios durante a pandemia". Por fim, a mestranda $\mathrm{J}$ disse que a pandemia modificou sua visão sobre educação porque "trouxe a reflexão em querer buscar mais diferentes metodologias para serem utilizadas na mediação do saber" e que após a pandemia "serei uma professora com outro olhar para educação e para as tecnologias que podem ser utilizadas com maior frequência na sala de aula”.

A partir dos dados apresentados e do contexto da pandemia Covid-19, percebemos que reflexões foram levantadas pelas mestrandas em meio aos desafios atuais, apontando assim para uma reformulação de práticas de ensino mais humanitárias e vinculadas com as TD. Na próxima seção, apresentaremos e analisaremos a ferramenta Google Meet, comparando nossos achados em torno dela com estes primeiros nas entrevistas com as mestrandas.

\section{Análise da ferramenta Google Meet para a realização de aulas remotas}

Após as entrevistas com as mestrandas, analisamos a plataforma Google Meet ${ }^{6}$ enquanto recurso para realização de aulas remotas no PPGECIM/UFAL, comparando nossos achados em torno dele com aqueles das entrevistas com as mestrandas. Analisamos seus recursos e possibilidades de intervenção de ensino e aprendizagem, realizando assim inferências em torno da qualidade das aulas que estão sendo realizadas no PPGECIM/UFAL no contexto remoto.

O Google Meet (figura 1) é uma plataforma de organização de reuniões que pode ser utilizada pelo professor para aulas remotas, sendo necessário o cadastro prévio em uma conta Google. Ele precisa gerar um link de acesso e ter os contatos de e-mail de cada estudante, podendo agendar (via Google Agenda) a data com os respectivos horários de suas aulas. Os convites são enviados para os e-mails dos estudantes e, no dia da aula, estes receberão um lembrete da realização dela de forma automática. A ferramenta conta com sistema de áudio e

\footnotetext{
${ }^{6}$ Disponível em : https://meet.google.com/
}

Revista Devir Educação, Lavras, vol.2, n.4, p.80-103 jul./dez., 2020. 
vídeo que devem estar ativos previamente (podendo ser ativados ou desativados a qualquer momento pelos estudantes ou professor). A versão paga do aplicativo permite a realização de reunião de até 250 pessoas, enquanto a versão gratuita não permite gravações de vídeochamadas e comporta a participação de até 15 participantes ao mesmo tempo e pode ser integrado a Google Classroom (Google Sala de aula), este permitindo processos assíncronos de ensino. Ativação de legendas, modo participação (passivo ou apresentador) também estão disponíveis.

\section{Figura 1-}

Google Meet

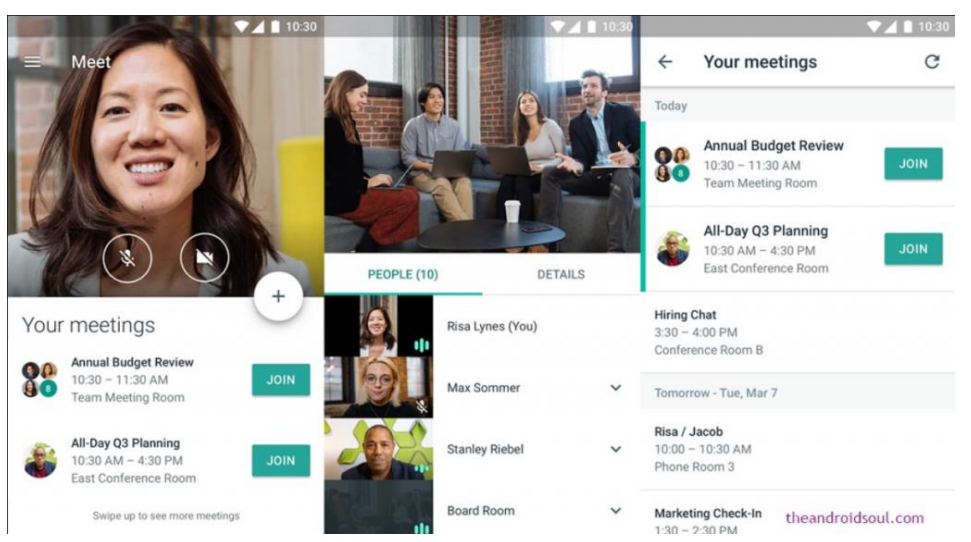

Plataforma utilizada nas

aulas remotas emergenciais

Fonte: encurtador.com.br/xNPX6

$\mathrm{Na}$ opção "Apresentar agora", qualquer pessoa que tenha entrado no Google Meet no modo apresentação, poderá explanar sobre um assunto utilizando documentos nos formatos PDF, Word ou PowerPoint nos modos tela inteira (a mesma tela será exposta para todos da reunião) ou no modo janela em que uma janela externa já aberta pode ser compartilhada com todos. Por último, a guia Google Chrome direciona a apresentação para sites selecionados previamente e que se deseja projetar na apresentação. O professor também pode gravar as aulas em "mais opções", auxiliando os estudantes em um contexto assíncrono.

A partir destes elementos no Google Meet, podemos afirmar que a plataforma é viável para o uso no contexto de aulas remotas emergenciais, mas apresenta algumas objeções que já haviam sido mencionadas nas falas das mestrandas na primeira fase do estudo. A mestranda $\mathrm{Y}$ afirmou previamente que as aulas emergenciais não possibilitam aproximação "olho no olho ou ouvir mais de perto o que o outro pensa". A partir da análise da plataforma, concordamos com esse ponto, uma vez que a atenção do professor não pode ser dada a todos ou quando alguém fala, o feedback para verificar quem está falando não é imediato, causando uma 


\section{QO DEVIR EDUCAÇÃO}

ISSN: 2526-849X

impressão de distanciamento. Outra objeção é que o chat é inviável para turmas muito grandes, o que impossibilita seu uso durante a aula e, quando em uso, pode ser direcionado à troca de informações ou esclarecimento de dúvidas.

Assim, para o contexto emergencial, concordamos com Arruda (2020) ao afirmar que aulas remotas vinculam os atores da educação, como nossas análises do Google Meet confirmaram, mas constatamos que existem perdas de feedback imediato, seja por problemas de conexão com a internet, como os dados das entrevistas apresentaram, ou pela impressão de distanciamento registrada na fala da mestranda Y e confirmada a partir de nossas análises da plataforma, o que pode influenciar nos percursos formativos dos estudantes.

\section{Considerações finais}

A partir dos achados em torno das entrevistas realizadas com as professoras de Biologia mestrandas do PPGECIM e de nossas análises e impressões em torno do Google Meet empregado nas aulas remotas do mestrado profissional a que estão vinculadas, concluímos que nossa hipótese de que a situação de pandemia ao provocar mudanças no processo de ensino aprendizagem alterou o processo formativo das mestrandas em relação à gestão do tempo, produção de dissertação/ acadêmicas e de produto educacional foi confirmada.

Os achados nas entrevistas permitem concluirmos que existe uma dicotomia dos impactos da pandemia em torno do processo formativo das mestrandas: aspectos favoráveis e outros que podem ser encarados como obstáculos. Por um lado, ganho inicial de tempo para a escrita do texto de dissertação; repensar as práticas de ensino articulada com as TD; poder repensar a educação em uma perspectiva holística; possibilidade de assumir práticas inovadoras de ensino após o término da pandemia; minimização do esgotamento físico por não ter que se deslocar para a universidade. Por outro lado, também foram encontrados: a sobrecarga de trabalho em casa; má gestão de tempo para cuidados da família e outras atividades; gerenciamento de emoções e ansiedade para produção acadêmica; mudanças no percurso da pesquisa devido ao fechamento das escolas; reformulação do projeto de pesquisa e produtos educacionais devido ao isolamento social; ausência de espaços físicos adequados 


\section{OD DEVIR EDUCAÇÃO \\ ISSN: 2526-849X}

no ambiente doméstico para estudar; ausência de hábitos interativos com TD; improvisação; ausência de atividades práticas.

Ao analisarmos o Google Meet, plataforma utilizada para aulas remotas no PPGECIM, chegamos às mesmas impressões dicotômicas em torno do impacto formativo das mestrandas, uma vez que a plataforma contribuiu para o desenvolvimento de aulas de modo a manter vínculo entre os atores do processo pedagógico, evitando o distanciamento deles por meses e estranhamento ao retornarem as aulas, assim como o cumprimento de prazos estabelecidos pelo PPGECIM, mas, por outro lado, o envolvimento dos estudantes entre si e com o professor gerou uma sensação de distanciamento devido à falta de feedback imediato, e os chats foram inviáveis quando a quantidade de estudantes foi alta. Neste último ponto, além das mestrandas de Biologia, o PPGECIM conta com mestrandos de Física, Química, Matemática e Pedagogia, o que aumenta o número de interações e dificuldade de feedback imediato pelo professor no chat. Assim, as aulas podem carecer de mediação pedagógica.

A partir dos achados neste estudo, recomendamos que outras investigações sejam realizadas em outros PPGECIMs, no campo da Biologia ou em outras áreas do conhecimento, afim de comparar resultados. Também recomendamos que estudos que envolvam a imersão na plataforma de aulas remotas sejam realizados, buscando termos uma perspectiva mais profunda em relação à qualidade das aulas que estão sendo realizadas e suas influências na formação. Este estudo apresentou limitações neste ponto, uma vez que realizamos inferências a partir das ferramentas que o Google Meet oferece para a condução das aulas e das evidências trazidas pela estudante $\mathrm{Y}$, imersa nas aulas remotas. Por fim, concluímos que em meio ao caos da pandemia Covid-19, novas visões sobre a educação e práticas envolvendo Tecnologias Digitais poderão ser desenvolvidas pelas mestrandas de Biologia na Educação Básica.

\section{Referências}

ARRUDA, Eucidio P. Educação remota emergencial: elementos para políticas públicas na educação brasileira em tempos de Covid-19. Revista de Educação a Distância, v.7, n.1, p.257-275, 2020. Disponível em: 
$<$ https://www.aunirede.org.br/revista/index.php/emrede/issue/view/15> Acesso em: 13 de jun. 2020.

BARDIN, Laurence. Análise do conteúdo. São Paulo: Edições 70, 2011.

BRASIL. Senado Federal. Lei de Diretrizes e Bases da Educação Nacional. 2ed. Brasília: Senado Federal, Coordenação de edições técnicas. Lei nº 9.394/96. Brasília: 2018.

FIALHO, Nadia R.; HETKOWSKI, Tânia M. Mestrados profissionais em Educação: novas perspectivas da pós-graduação no cenário brasileiro. Educar em Revista, Curitiba, n.63, p.19-34, 2017 . Disponível em:

$<$ https://www.scielo.br/scielo.php?script=sci_abstract\&pid=S010440602017000100019\&lng=en\&nrm=iso\&tlng=pt> Acesso em 25 jun. 2020.

FORMIGA, Marcos. A terminologia da EaD. In: LITTO, Frederico M.; FORMIGA, Marcos. Educação a distância: o estado da arte (Org.). São Paulo: Pearson Education do Brasil, 2009. p.39-46.

IBERNÓN, Francisco. Formação permanente do professorado: novas tendências. São Paulo: Cortez, 2009.

MOREIRA, José A.; HENRIQUE, Susana.; BARROS, Daniel. Transitando de um ensino remoto emergencial para uma educação digital em rede, em tempos de pandemia. Dialogia, São Paulo, n.34, p.351-364, 2020. Disponível em:

$<$ https://periodicos.uninove.br/index.php?journal=dialogia\&page=article\&op=view\&path\%5 B\%5D=17123> Acesso em: 26 jun. 2020.

MOREIRA, Marco A.; NARDI, Roberto. O mestrado profissional na área de ensino de Ciências e Matemática: alguns esclarecimentos. Revista brasileira de ensino de ciência e tecnologia, v.2, n.3, p.1-9, 2009. Disponível em:

<https://periodicos.utfpr.edu.br/rbect/article/view/549/398> Acesso em: 23 jun. 2020.

SAMPIERI, Roberto H.; COLLADO, Carlos F.; LUCIO, Maria P. Metodologia de pesquisa qualitativa. Porto Alegre: Penso, 2013.

SANTOS JÚNIOR, Verissimo B.; MONTEIRO, Jean.; Educação e Covid-19: as tecnologias digitais mediando a aprendizagem em tempos de pandemia. Encantar-Educação, Cultura e Sociedade, Bom Jesus da Lapa, v.2, p.1-15, 2020. Disponível em:

<https://www.revistas.uneb.br/index.php/encantar/article/view/8583> Acesso em: 22 jun.2020.

STRAUSS, Anselm.; CORBIN, Juliet. Pesquisa qualitativa: técnicas e procedimentos para o desenvolvimento de teoria fundamentada. 2ed. Porto Alegre: Artmed, 2008.

SZYMANSKY, Heloisa. Entrevista reflexiva: um olhar psicológico sobre a entrevista em pesquisa. In: SZYMANSKY, Heloisa; ALMEIDA, Laurinda R.; PRANDINI, Regina C. (org.). A entrevista na pesquisa em Educação: a prática reflexiva. Brasília: Liber Livro, 2011, p.9-61.

TARDIF- Maurice. Saberes docentes e formação profissional. 17ed. Petrópolis: Vozes, 2014. 
VERCELLI, Lígia C. Aulas remotas em tempos de Covid-19: a percepção de discentes de um programa de mestrado profissional em Educação. @ mbienteeducação, v.13, n.2, p.47-60, 2020. Disponível em:

<http://publicacoes.unicid.edu.br/index.php/ambienteeducacao/article/view/932> Acesso em: 20 jun. 2020.

YIN, Robert K. Pesquisa qualitativa do início ao fim. Porto Alegre: Penso, 2016.

Recebido em 01/07/2020

Aprovado em 08/08/2020

Revista Devir Educação, Lavras, vol.2, n.4, p.80-103 jul./dez., 2020. 